\title{
A century of spinosaurs - a review and revision of the Spinosauridae with comments on their ecology
}

\author{
HONE David William Elliott ${ }^{1,}{ }^{*}$ HOLTZ Thomas Richard Jnr ${ }^{2}$ \\ 1 School of Biological and Chemical Sciences, Queen Mary University of London, London, E1 4NS, \\ $U K$ \\ 2 Department of Geology, University of Maryland, College Park, MD 20742 USA
}

\begin{abstract}
The spinosaurids represent an enigmatic and highly unusual form of large tetanuran theropods that were first identified in 1915. A recent flurry of discoveries and taxonomic revisions of this important and interesting clade had added greatly to our knowledge, however, spinosaur body fossils are generally rare and most species are known from only limited skeletal remains. Their unusual anatomical adaptations to the skull, limbs and axial column all differ from other large theropods and point to an unusual ecological niche and a lifestyle intimately linked to water.
\end{abstract}

Keywords: Theropoda, Megalosauroidea, Baryonychinae, Spinosaurinae, palaeoecology

E-mail: d.hone@qmul.ac.uk

\section{Introduction}

The Spinosauridae is an enigmatic clade of large and carnivorous theropods from the Jurassic and Cretaceous that are known from both Gondwana and Laurasia (Holtz et al., 2004). Despite their wide temporal and geographic distribution, the clade is known primarily from teeth and the body fossil record is extremely limited (Bertin, 2010). As such, relatively little is known about this group of animals, although their unusual morphology with regard to skull shape, dentition, dorsal neural spines and other features mark them out as divergent from the essential bauplan of other non-tetanuran theropods (Fig 1). They likely occupied different ecological niches to other theropods, as despite evidence of a broad diet (Charig \& Milner, 1997; Buffetaut et al., 2004), these animals clearly spent a considerable amount of their time in and around water (Amiot et al., 2010a; Sales et al., 2016) and could be considered semi-aquatic (Ibrahim et al., 2014). They certainly show adaptations towards capturing aquatic prey including fish (Charig \& Milner, 1997; Rayfield et al., 2007).

Despite the poor fossil record for this clade, the spinosaurs have enjoyed a recent increase in scientific interest with a number of new taxa described in recent years (Kellner et al., 2011; Allain et al., 2012) and new finds of existing taxa bolstering the number of specimens (Dal Sasso et al., 2005; Mateus et al., 2011; Naish, 2011; Ibrahim et al., 2014) and increasing their known temporal and geographic ranges (Hone et al., 2010; Buffetaut, 2012). Given their apparent aberrant morphology and 
behavior as well as their unusual local distributions (frequently either vanishingly rare, or quite abundant) the spinosaurids are perhaps some of the most ecologically interesting of theropods. Here we review the taxonomic identifications of the spinosaurs and their ecological role in Mesozoic ecosystems.

\subsection{History}

The first spinosaur recognised is Spinosaurus aegyptiacus as described by Ernst Stromer (1915). This was based on a specimen from the Egyptian desert that included parts of the skull and a number of dorsal vertebrae that showed the now characteristic giant neural spines of these animals. The loss of this specimen as a result of an allied bomb during World War II (Smith et al., 2006) severely restricted our knowledge and research on this most unusual animal. However, discoveries in the late 1900s, starting with the British Baryonyx (Charig and Milner, 1986), allowed for the reassessment of previous finds. Even so, it was some time before these two genera were united into a single clade, Buffetaut (1992) was the first to suggest that Baryonyx may have been close to Spinosaurus, an idea initially rejected by some (e.g. Charig \& Milner, 1997), but that is now well supported.

Material now recognised as spinosaur in origin in fact was first described by Richard Owen in the early 1840s based on teeth he obtained from Gideon Mantell (see Buffetaut, 2010 for details). These teeth were considered at the time to belong to a crocodilian (and indeed spinosaur teeth are similar to crocodilians) but may now be referred to Baryonyx (Buffetaut, 2010, Mateus et al., 2011). Similarly, fragmentary teeth from Algeria that belong to Spinosaurus predate Stromer's discoveries (Buffetaut, 2010) and material recovered from the Tendaguru expeditions of the 1920s were only identified as spinosaurid in origin nearly a century later (Buffetaut, 2008), although this referral is controversial (Rauhut, 2011).

Since the discovery of Baryonyx, there has been something of a flood of spinosaurs given the paucity of the previous century. In addition to a large number of taxa of questionable validity (and often very limited completeness), important discoveries include the spinosaurines Irritator (Martill et al., 1996) and Oxalaia (Kellner et al., 2011) from Brazil, and the baryonychines Suchomimus (Sereno et al., 1998) from Niger and Ichthyovenator (Allain et al., 2012) from Laos (see Bertin, 2010 for a thorough list of spinosaurid material). Additional finds have been related to named taxa (e.g. Buffetaut, 2008; Mateus et al., 2011) has also extended our knowledge and may yet yield new taxa (see Naish, 2011).

Although most of this new generation of specimens are very incomplete, the additional information available combined with important new techniques available (e.g. Finite Element Analysis, assessments of isotopes) has led to a new interest in the clade. However, there are limitations to the available information leading to confusion and disagreement over key areas of spinosaur research.

\subsection{Limitations}

The paucity of body fossils generally and the lack of completeness of those that have been found does limit our understanding of spinosaurs. For example the Baryonyx holotype is known from a partial skull, at least some elements of the cervical, dorsal, and caudal series, cervical and dorsal ribs, the pectoral girdle and much of the forelimbs and partial hindlimbs (Charig \& Milner, 1997) and Suchomimus is similarly well-known though this coverage of the skeleton is made up from multiple specimens (Sereno et al., 1998). Most other clades of theropods are represented by either multiple good specimens of single species, or at least near-complete specimens of single species. No spinosaur has yet been found with a complete skull or a complete limb, and there are only few complete series for a 
single part of the axial column.

Therefore fundamental assessments of issues such as mass or body length are highly uncertain (e.g. see Dal Sasso et al., 2005 and Thierren \& Henderson, 2007), and reconstructions of species are often based on multiple specimens or taxa. Claims of extraordinary sizes should be tempered without complete or near-complete specimens to work from, though all spinosaurs known to date were certainly large-bodied theropods. Similarly, comparisons between specimens are hampered by the lack of overlapping material and the naming of fragmentary material and coupled with the often brief descriptions of key specimens and taxa, the taxonomy of the spinosaurs is at best, problematic.

Various taxa have been named that have subsequently synonymised with others or considered nomina dubia, and while such revisions are not uncommon for Mesozoic theropods, the number is high considering the relatively recent discovery of much of the material. For example, Suchomimus has been suggested to be congeneric with Cristatusaurus and that both should be considered to reside within Baronyx, and that Irritator may be congeneric with Spinosaurus (Sues et al., 2002). Charig and Milner (1997), Sereno et al. (1998) and Sues et al. (2002) all considered that Angaturama may be congeneric with Irritator, and in fact Sereno et al. (1998) even suggested the holotype of the former may even represent part of the same specimen as the latter. Sereno et al. (1998) considered Sigilmassasaurus to be congeneric with the allosaurid Carcharodontosaurus, although Ibrahim et al., (2014) more recently suggested it to belongs to Spinosaurus. Evers et al. (2015) regard Sigilmassaurus as a spinosaurid but one distinct from Spinosaurus, and indeed possibly closer to Baryonyx and Ichthyovenator.

However, all of the above examples were considered separate and valid taxa by Holtz et al., (2004) in their review of tetanurans, and all (except Sigilmassasaurus which was not mentioned) were also considered distinct by Kellner et al. (2011), demonstrating the lack of agreement over the taxonomy of this clade. It is beyond the scope of this paper to assess the taxonomy of these various specimens and the putative congeneric or conspecific status of various taxa in detail, but a revision would appear to be overdue. Such a revision is greatly hindered by many of these taxa having only been described in cursory initial reports; we await detailed monographic treatments for most of these species.

\section{Taxonomy \& Systematics}

The phylogenetic position of the spinosaurs has varied in various cladistic analyses of the non-coelurosaurian theropods. Most analyses have identified a close relationship to members of Megalosauridae with the two likely sister-taxa within the Megalosauroidea (Charig \& Milner, 1997; Rauhut, 2003; Benson, 2010; Allain et al., 2012; Carrano et al., 2012). This position is supported by characters including the shape of the jugal ramus of the postorbital, a step to the hyposphene in dorsal vertebrae, and the presence of tall dorsal neural spines (Benson, 2010).

The monophyly of the Spinosauridae is well supported (e.g. Holtz et al., 2004; Carrano et al., 2012) and can be defined by: the presence of a premaxillary rosette; external nares positioned posteriorly to the premaxillary tooth row (all Sereno et al., 1998); the greatly elongate maxillae; the subcircular tooth crowns (in cross-section); and the still greater elongation of the dorsal neural spines to greater than twice the height of the centrum in addition to further characters (all Benson, 2009); the presence of striations on tooth crowns; anterior carina situated at the base of the crown on maxillary and dentary teeth; the presence of a ventral keel in posterior-most cervical and anterior dorsal vertebrae; the presence of pneumaticity/'webbing' at base of neural spines in middle to posterior dorsals (all Evers et al., 2015). There are also additional numerous potential synapomorphies of the group that are 
currently ambiguous (Evers et al., 2015).

The origins of the Spinosauridae remain somewhat obscure. The oldest unquestionable spinosaurid is Baryonyx walkeri of the Barremian of Great Britain. However, a sister group relationship with Megalosauridae requires a split between these theropod groups before the oldest known representatives of either clade; in this case, it would be the Bajocian-aged megalosaurids Duriavenator and Magnosaurus. Thus, there is a seemingly undocumented phase of the spinosaurid lineage from 170 until $130 \mathrm{Ma}$.

There are, however, fragmentary remains of possible Jurassic spinosaurids. These include Ostafrikasaurus crassiserratus, a pair of isolated teeth of middle-to-late Tithonian age (148-145 Ma) (Buffetaut 2012), and Serrano-Martínez et al. (2015) describe a worn isolated tooth from the Middle Jurassic (?Bathonian) "Argiles de l'Irhazer" which they provisionally refer to Spinosauridae.

Additionally, Allain et al. (2012) have observed that the large isolated manual ungual from the Kimmeridgian aged Morrison Formation in the USA traditionally considered as coming from the megalosaurid Torvosaurus, is not actually associated with other specimens of that dinosaur. Given the similar morphology of this claw and those of known spinosaurids, this may also represent a Late Jurassic member of the spinosaurid line (Allain et al., 2012).

Those members of Spinosauridae for which significant parts of the anatomy are recovered have been divided into two sister taxa, the Spinosaurinae and Baryonychinae (Fig 3) - a split first recognized by Sereno et al. (1998) with each defined by major anatomical traits. In the Baryonychinae these include a V-shaped premaxillary-nasal suture and the presence of webbing on the posterior dorsal neural spines (Benson, 2009), and members of Spinosaurinae show a greatly reduced size of premaxillary tooth 1 (Sereno et al., 1998) and the absence of serrations on the teeth of that also exhibit reduced curvature or are straight (Benson, 2009).

Here we tentatively follow a number of taxonomic revisions that have synonymised a series of putative spinosaur taxa. In particular, taxa based on isolated teeth are provisionally considered non-diagnostic although Ostafrikasaurus is listed given its significance in documenting a potential Jurassic spinosaurid with traits demonstrably distinct from other definite members of the clade. Teeth belonging to spinosaurines are typically described as having no serrations, strong ornamental ridges on the enamel, and a more circular cross-section, with baryonychines showing the reverse pattern (fig 4). However almost every combination of serrations, ornaments and cross-section have been described for each clade at some point (see Hone et al., 2010). As such, teeth are especially problematic as being diagnostic for the spinosaurids and taxa based on them require special attention, although see also Hendrickx and Mateus (2014) on the diagnoses of spinosaur teeth. As noted above however, a thorough review of the clade is generally required to confirm these patterns.

It must also be noted that the situation as to the taxonomic identity of Cenomanian North African spinosaurids is currently under particular debate. The holotype specimen of Spinosaurus aegyptiacus is now lost and fossils from a nearby locality that were designated as "Spinosaurus B" by Stromer (1934) have similarly, since been destroyed. Stromer regarded these latter specimens as possibly representing a distinct taxon, but did recognize that they were different from those of the holotype due to individual variation or sexual dimorphism. Many additional fossils of spinosaurids have been recovered (many for commercial sale) from the roughly coeval Kem Kem Beds of Morocco. Among these are the specimens named Spinosaurus maroccanus and Sigilmassasaurus brevicollis by Russell (1996). Furthermore, a specimen of a tall-sailed subadult spinosaurid from the Kem Kem Beds was described by Ibrahim et al. (2014) 
Conflicting taxonomic hypotheses have been proposed concerning these various fossils. Ibrahim et al. (2014) regard all these as belonging to the same species (Spinosaurus aegyptiacus). Alternatively, Evers et al. (2015) regard Spinosaurus maroccanus and Sigiilmassaurus brevicollis as belonging to the same spinosaurid taxon (under the latter name), but this taxon is regarded as distinct from Spinosaurus (indeed, they noted similarities between the Kem Kem species and baryonychines) - a position broadly supported by Hendrickx et al. (2016). Evers et al. (2015) also described additional fossils from the same assemblage representing a second unnamed spinosaurid (previously suggested based on tooth enamel patterning by Richter et al. (2013)). This taxonomic quandary would seem to be presently unresolvable; we do not have sufficient specimens to eliminate the possibility of ontogenetic variation and/or sexual dimorphism to explain the differences, especially given the disarticulated nature of the specimens.

Below are revised definitions of the major members of the Spinosauridae. In most cases parts of the original definitions have been removed simply because new finds have superseded them and shown that previously diagnostic characteristics are more widespread within the clades. For example, Charig and Milner (1997) used the restriction of the posterior part of the premaxilla to form the 'terminal rosette' as diagnostic for both Baryonyx, but this feature is universal among spinosaurid remains for which this part of the skull is knonw (Kellner \& Campos, 1996; Kellner et al., 2011; Sereno et al., 1998; Dal Sasso et al., 2005). Differences lie within the shape of this rosette (see Bertin, 2010, his Figure 4) and the details may be diagnostic (see Kellner et al., 2011) but the mere presence of this feature is not an autapomorphy of Baryonyx. Not included in this list are unnamed spinosaurids (or possible spinosaurids) from the Middle Jurassic of Niger (Serrano-Martínez et al., 2015), the Early Cretaceous of Australia (Barrett et al., 2011: but see Novas et al., 2013, for a dissenting view), and the Early Cretaceous (Buffetaut et al., 2008) and Late Cretaceous of China (Hone et al., 2010).

\subsection{Spinosauridae incertae sedis:}

Ostafrikasaurus crassiseratus: teeth only moderately compressed labiolingually (relative to condition in Cretaceous spinosaurids); enamel wrinkled, with ridges more numerous and more pronounced on lingual face than labial; anterior and posterior carinae serrated, with relatively larger (2-4 denticles per $\mathrm{mm}$ ) than in Cretaceous spinosaurids. Modified from Buffetaut, 2012.

\subsection{Baryonychinae:}

Ichthyovenator laosensis: a dorsosacral sinusoidal sail; penultimate dorsal neural spine is > three times centrum height with anterodistal finger-like process; fanshaped sacral neural spines 3 and 4; transverse processes of first caudal vertebra with sigmoid profile in dorsal view; deep prezygapophyseal centrodiapophyseal fossae on the first caudal vertebra; long iliac blade with ilium/pubis length ratio higher than in any other theropods; posterior dorsal ribs articulated with sternal complex; proximal pubic plate with obturator and pubic notches; large ischial plate with ischial foramen; and mediolaterally flattened ischial shaft. Modified from Allain et al., 2012

Baryonyx walkeri: Small median knob at posterior end of conjoined nasals, cruciform in dorsal view with anterior limbs of cross drawn forwards into low, thin, medial crest (similar to that of Irritator); occiput deep, with paraoccipital processes directed horizontally outwards; basipterygoid processes descend far below basioccipital, diverging laterally only slightly (also in Irritator); axis small, with well-developed hyposphene; cervical vertebrae with flat zygopophyses and well-developed 
epipophyses; neural spines generally short of vertebrae except those of the proximal caudals (c.f. Suchomimus); cervical ribs short, crocodyloid and slightly overlap; radius less than half the length of the humerus; ischium with obturator flange proximally continuous with anterior margin. Modified from Charig and Milner, (1997).

Suchomimus tenerensis: elongate posterolateral premaxillary process that nearly excludes the maxilla from the external naris (may be present in Baryonyx); broadened and heightened posterior dorsal, sacral, and anterior caudal neural spines (only in proximal caudals in Baryonyx); robust humeral tuberosities (may be present in Baryonyx); and hook-shaped radial ectepicondyle. Modified from Sereno et al., (1998).

\subsection{Spinosaurinae:}

Oxalaia quilombensis: maximum expansion of the distal end of the premaxillae between the 3rd and 4th alveoli (also in Suchomimus); presence of two replacement teeth associated with the 3rd functional tooth; diastema between the 5th and 6th premaxillary teeth (shorter than in Spinosaurus); ventral portion of the premaxillae very sculptured. Modified from Kellner et al., (2011).

Irritator challengeri: Nasals with prominent median bony crest that terminates posteriorly in knob-like, somewhat dorsoventrally flattened projection (similar to that of Baryonyx); dorsal surface of parietals facing posterodorsally and vertical axis of braincase inclined anteroventrally; posterior surface of basisphenoid with deep, dorsoventrally oval median recess; surangular with broad lateral shelf. Sues et al., (2002).

Spinosaurus aegypticus: A change from very large anterior teeth to minute middle teeth to again large posterior teeth in the dentary; an extremely enlarged, anteroventrally open anterior myliohyoid foramen in the splenial; strong, rounded expansion at the base of the neural spines. Evers et al., (2015 - modified from Stromer, 1915). In addition, Ibrahim et al., (2014) designated a neotype for S. aegypticus, which, if this assignment is warranted (see Evers et al., 2015) would provide a different diagnosis as follows: external naris and narial fossa small; premaxilla excluded from the border of the external naris; hourglass-shaped and elongated dorsal centra; dorsal neural spine height up to ten times greater than centrum height; greatest anteroposterior dorsal neural spine width below spine apex; proximal one-third of dorsal neural spines textured externally by vertical striae; long bones lack open medullary cavity; length of ilium larger than dorsoventral length of femur; femur strongly bowed anteriorly with fourth trochanter hypertrophied, extending along $25 \%$ of the femoral shaft; pedal digit I long, digit I-1 phalanx longest non-ungual phalanx in the pes; pedal unguals broader than deep with length almost four times proximal depth; pedal unguals with flat ventral surface. Modified from Ibrahim et al., (2014).

Sigilmassaurus brevicollis: mid-cervical vertebrae with offset, transversely convex, strongly rugose triangular platform at the posterior end of the ventral side that is confluent with a ventral keel anteriorly; anteriorly broad centroprezygapophyseal lamina with no or strongly reduced centroprezygapophyseal fossa already in anterior mid-cervical vertebrae; reduced neural arch lamination with no or incomplete distinction between anterior and posterior centrodiapophyseal laminae in posterior cervicals and first dorsal; small elongate fossa on either side of the base of the neural spine in last cervical and first dorsal 
vertebrae. From Evers et al., (2015).

\section{Discussion}

\subsection{Anatomy}

In addition to the characters listed above that help define the Spinosauridae and the two included clades, a variety of features do mark out the spinosaurids are rather different from other tetanurans or indeed other theropods. Many of these are linked to their inferred unusual ecology and have strong functional signals.

The cranium is proportionally long and both narrow laterally and short dorsoventrally (Sues et al., 2002). The jaws terminate in a 'rosette' where there is a constriction close to the maxillary-premaxillary suture and then the premaxilla is laterally expanded and rounded in dorsal view (See Fig 5). The mandible conforms with this shape, with a notch in the anterior part of the dentary and then an expanded tip. The maxillary and dentary tooth rows may be sinusoidal in lateral view. In addition to their unusual shape, the teeth of spinosaurids are unevenly distributed with large teeth in the anterior premaxilla, smaller teeth in the posterior premaxilla /anterior maxilla, and then large teeth again in the mid-maxilla. The premaxillary tooth count of six to seven is higher than the four that characterises most members of Tetanurae. The nares are retracted and lie well posterior to the anterior margin of the skull and are somewhat dorsally positioned (Sues et al., 2002). Several spinosaurs also exhibit a bony secondary palate formed by an extension of the maxilla (Rayfield et al., 2007).

Spinosaurs have characteristically elongate neural spines on their vertebrae. Although this feature does appear in other theropods (e.g. Concavenator - Novas et al., 2013) and even ornithischians (e.g. Ouranosaurus - Taquet, 1976) it is taken to an extreme in the spinosaurs. Baryonyx exhibits only limited expansion with only some posterior vertebrae showing this (Charig \& Milner, 1997), and although in Suchomimus this extends along the whole preserved vertebral column (Sereno et al., 1998), in neither case is the neural spine much over twice the height of the centrum, and these are somewhat simple plates. In Ichthyovenator however the neural spines are more than three times the height of the centrum, expand dorsally to form a triangle in lateral view, and even have a projection from them (Allain et al., 2012) and in Spinosaurus the neural spines can be extraordinarily long in some dorsals (Stromer, 1915) and at least some Moroccan cervical vertebrae show unusually long neural spines (Evers et al., 2015).

Although the forelimbs of megalosauroids tend to be robust, those of spinosaurs are unusually so. The radius is robust and typically close to only half the length of the humerus (Charig \& Milner, 1997), while the ulna (although also short) shows an enlarged olecranon process (Sereno et al., 1998). The ungual of the first manual digit is also unusually large (Charig \& Milner, 1997), though otherwise is typical for tetanurans.

In most spinosaurids the pelvis and (where known) the hindlimb are not considerably different in proportion and anatomy from those of other megalosauroids theropods. In Spinosaurus, however, the ilium is proportionately smaller than those of other large theropods, and the limb bones have no significant medullary cavity (Ibrahim et al., 2014).

\subsection{Distribution}

Spinosaur body fossils remain generally rare and are known from far fewer remains than comparable clades, despite their large size and apparent tendency to exploit aquatic environments 
(Hone et al., 2010). They can be locally common (Benyoucef et al., 2015) but overall are known from a limited number of localities and skeletal remains (jaw tips aside) are very rare. Numerous teeth are known for spinosaurs and can be very common in some localities. Spinosaur teeth are arguably easier to identify to the clade level than those of some other larger bodied theropods, which might partly explain why they are so common (i.e. teeth can be positively identified as spinosaurid, rather than say Coelurosauria or even Theropoda indet.). Equally however, worn spinosaur teeth may be hard to separate from those of sympatric crocodilians.

The geological rage of the spinosaurids is extensive with the earliest records are from the Tithonian (Buffetaut, 2012) c. $147 \mathrm{Ma}$ (and possibly in the Bathonian, c. $168 \mathrm{Ma}$ (Serrano-Martínez et al., 2015)) with the most recent being the Late Santonian (Hone et al., 2010) c. 85 Ma - both records are based on teeth. However, given their phylogenetic position among early megalosauroids, the spinosaur lineage must extend back to at least the Middle Jurassic, and perhaps even the Early Jurassic.

The spinosaurids also have a wide geographical distribution. Despite the limited remains recovered, spinosaur fossils have been recovered extensively in Europe (UK, France, Portugal, Spain), and North Africa (Morocco, Niger, Egypt, Tunisia, Algeria) and numerous other localities across the world including Brazil, Laos, Thailand, China, Tanzania and even Japan (see Bertin, 2010) and Australia (Barrett et al., 2011: but see Novas et al., 2013, for uncertainty for this assignment). Appearing in Asia, Europe and South America in the Cretaceous, the spinosaurs presumably dispersed to the latter South America via the North from either Asia or Europe. Bizarrely however, they are currently unknown from any of the considerable number of well-studied North American Cretaceous localities. Only one element, the above mentioned Jurassic-aged ungual that has been tentatively identified as having links to the spinosaurs (Allain et al., 2012), may currently tie them to North America.

Spinosaur fossils are generally rare, and thus it is not impossible that future discoveries will document then in North America. Nevertheless, the extensively sampled fossil beds of the Jurassic and Cretaceous North America have failed to yield any definitive evidence of Spinosauridae so far, despite their diagnostic teeth. As has been noted (Buffetaut, 2008; Allain et al., 2012) the very limited record of spinosaur material makes it currently difficult to make any assertions about their origins or geographic spread.

\subsection{Ecology and behaviour}

Stromer himself (1915) did not speculate on any particular difference in diet or food acquisition in Spinosaurus compared to other theropods. Subsequently, however, the diet of spinosaurs has long been a subject of great discussion. The idea that these animals were primarily or at least partly piscivorous (Taquet, 1984; Charig \& Milner, 1986) has been a common suggestion. The morphology of the skull and teeth in particular are similar to those of modern crocodilians (Holtz, 1998) and to extinct animals (phytosaurs, champosaurs, some pterosaurs) inferred to have similarly piscivorous diets. This hypothesis is well supported by both function analyses (Rayfield et al., 2007) and critically the presence of acid-etched fish scales preserved with the holotype of Baryonyx (Charig \& Milner, 1986).

As with extant crocodilians, (and unlike almost all other theropods), spinosaurs exhibit the terminal rosette in the premaxillae, sinusoidal tooth margins, enlarged anterior teeth, teeth are typically straight with limited serrations and are close to circular in cross-section (Charig \& Milner, 1986). The reduced or absent tooth serrations would reduce cutting power but their robust and vertically orientated tooth crowns would resist high loading and would be suitable for both impaling and holding potential 
prey (Sues et al., 2002). The bony secondary palate and reduced antorbital fenestra seen in spinosaurs will reduce torsion (Rayfield et al., 2007) and functionally the rostrum of Baryonyx at least would operate much more like a modern gharial (Gavialus) than other theropods (Rayfield et al., 2007). Finally, spinosaurs possessed an unusual set of enlarged neurovascular canals in the rostrum (Dal Sasso et al., 2005) that might have possessed crocodilian-like pressure receptors (Ibrahim et al., 2014) that would function in capture of prey in water. Such a complex of neurovascular canals have been observed in modern and extinct crocodyliforms (Soares, 2002) and plesiosaurs (Foffa et al., 2014) but also recently in the allosauroid Neovenator (Barker et al., 2015).

Collectively this suite of features suggests a very different mode of prey capture and processing to other theropods and something more crocodile-like with a tendency to focus on aquatic prey. However, given the paucity of spinosaur finds, they have been demonstrated to have had a remarkably varied diet (Bertin, 2010). In addition to fish, Baryonyx has the bones of a juvenile iguanodontid in the stomach region (Charig \& Milner, 1997), and there are a series of pterosaur vertebrae with a spinosaur tooth embedded in them (Buffetaut et al., 2004).

Spinosaurs have also been suggested to be specialist scavengers with the long jaws being suitable for probing into carcasses to feed on the viscera (Kitchener, 1987). This hypothesis has been strongly challenged on functional grounds (Charig \& Milner, 1997) and it also overlooks the fact that internal organs are typically one of the first parts tackled by a carnivore (Blumenschine, 1986) so an actual predator that made the kill would likely have consumed these parts of carcass before a scavenging spinosaur reached the carcass. The occasionally high numbers of spinosaurs in certain systems (Benyoucef et al., 2015; Sales et al., 2016), (and often the lack of other large dinosaurs / theropods) also suggests a primarily scavenging model would not be viable.

The unusually robust forelimbs with the enlarged ungual on digit one have been an enigma and controversial. Spinosaurus had been depicted as a quadruped in the popular literature, (e.g. Halstead, 1975; Glut, 1982) but with almost no material available this remained conjecture. Charig and Milner (1986) initially suggested that Baryonyx might be facultatively quadrupedal but later ruled this out given the proportional very short nature of the forelimb (Charig \& Milner, 1997). As with other theropods, there is no reason to a priori assume that the forelimb could pronate and the animals could rest or walk on their palms. This does not necessarily prevent the forelimbs being used in resting or locomotion (as demonstrated by the manus prints of a resting theropod - Milner et al., (2009)) but it would be unusual if the forelimb showed no adaptations to terrestrial locomotion if this were the norm. Assessment of the recent suggestion that Spinosaurus may have been adept quadrupedally (Ibrahim et al., 2014) is hampered by the lack of definitive (and in particular, associated) forelimb material for the genus.

The large claws of spinosaurs have been suggested to facilitate entry into carcasses of prey or scavenged kills (Kitchener, 1997). The latter is rather redundant in the light of the arguments against specialized scavenging and the former implies the regular predation of large prey which is also unlikely (see below). These claws have also been suggested to have been used to hook fish from the water in the manner of modern bears (e.g. Charig \& Milner, 1986) though the redundancy of two independent prey catching systems (the claws and the mouth) has been noted (Kitchener, 1987). Similarly, bears may well be using their claws as they have proportionally long arms and short snouts making the former a practical methods for recurring food, which is the opposite of spinosaurs (fishing with arms held under the head that could not be seen by eyes would seem at best, a sub-optimal strategy).

It is also not clear how such a short and robust forelimb with presumed limited pronation would 
be a suitable organ for trapping aquatic prey. To date the arms have actually attracted little commentary despite the unusual morphology of the humerus (Sereno et al., 1998) and ulna (Charig \& Milner, 1997). However, the short and robust nature of the limb and in particular the enlarged olecranon in combination with the enlarged unguals do have much in common with animals that engage in scratch-digging and hook-and-pull digging (Hildebrand \& Goslow, 2001), including other theropods (Senter, 2005). The relatively narrow width of the enlarged ungual (Charig \& Milner, 1997) and lack of a spade-like spread to the limbs imply digging into harder substrates rather than moving large quantities of softer materials.

Digging is not the only hypothesis that would fit the available (currently limited) information but it should be considered. Spinosaurs would have had to excavate nests and may have been digging in some areas for water or to reach certain prey items, and unusual features may be selected for even if they are rarely used (Hone \& Faulkes, 2014), including adaptations to dig seen in dinosaurs (Fowler \& Hall, 2011). Certainly the arms of these animals were adapted for some purpose given their differences to other tetanuran theropods and greater attention should be paid to them in the future.

The evidence that spinosaurs spent considerable time in and around water is highly convincing (so much so it has even been used as an example as to restoring the ecology of extinct taxa - Hone \& Faulkes, 2014) although they are also often found in association with arid environments (Amiot et al., 2010b). In addition to the obvious tendency to tackle aquatic prey, isotopic analysis has shown that some spinosaur teeth retain a signature close to that of semi-aquatic crocodilians and chelonians (Amiot et al., 2010a) suggesting extended periods in water.

Based in part on an apparently reduced hindlimb and pelvis, Ibrahim et al., (2014) have suggested that Spinosaurus in particular was especially well-adapted to an aquatic lifestyle and may have been partially quadrupedal. Similarly, Spinosaurs is reported to have had unusually reduced medullary cavities in the long bones and may be unusually dense as with other aquatic and semi-aquatic amniotes (Ibrahim et al., 2014).

However, the idea that spinosaurs generally were fully adapted to an aquatic lifestyle and were akin to that of modern and extinct animals considered semi-aquatic (e.g. crocodilians, many chelonians, otters, hippopotamus, aetosaurs) is limited. Although the external nares are retracted in spinosaurs and are not present at the tip of the rostrum as in other theropods, they are laterally positioned and not dorsally located (Charig \& Milner, 1986). A partially or fully submerged animal would be obliged to raise much of the head above the water to breathe, and so perhaps these animals were typically more terrestrial and instead waded and dipped into the water to feed (Charig \& Milner, 1997) as with many modern shore-birds. This may for example explain the retracted, but not dorsally positioned, nares. Similarly, not all isotopic signatures support a highly aquatic lifestyle and some teeth referred to Spinosaurus give results that are common to other terrestrial theropods and less like semi-aquatic animals (Amiot et al., 2010b).

It has also been suggested that spinosaurs may not be suitable for tackling proportionally large prey (Sues et al., 2002 on Irritator) although this is likely a common pattern for theropods as a whole (Hone \& Rauhut, 2010). In contrast, Hendrickx et al. (2016) suggested that spinosaurs took large prey, though as this is in the context of their ability for the width of the jaws to expand when opening this is perhaps better considered an ability to swallow larger items than might be expected, rather than absolutely large prey items. Hone et al., (2010) suggested that spinosaurs typically had narrow ecological niches (despite being generalists) explaining their overall rarity but occasional high numbers when conditions were advantageous to their unique combination of characters. This hypothesis echoes 
the comments of Holtz (1998) who noted that the increased terrestrial mobility of a spinosaur over a crocodile, and the increased ability to exploit aquatic food sources compared to other theropods would put spinosaurs in an unusual ecological position. Certainly the broad diet of spinosaurs echoes that of modern crocodilians (including that of the highly specialised gharial - Saikia, 2013) and suggests that they exploited resources in a manner that differs from both contemporary aquatic and terrestrial carnivores, and this is supported by the mixed data from isotope signatures for example.

Spinosaurs typically exhibit two different structures that could be interpreted as socio-sexual signals. Firstly, they commonly have some form of cranial crest on the posterior part of the nasals (Charig \& Milner, 1986; Sues et al., 2002; Ibrahim et al., 2014) and more obviously the greatly expanded neural spines that form some kind of 'sail'. The cranial crests have been little commented upon but are close in form to those seen in numerous other theropods being typically small and situated close to, or above, the eyes (Hone et al., 2012). In the absence of compelling counter-evidence at the present time these features are perhaps best interpreted as some form of socio-sexual display structure (Fig 6).

The sail itself varies enormously being very limited in Baryonyx (though still larger than almost any other non-spinosaurid theropod) and hypertrophied in Spinosaurus. This feature has been suggested to have borne some kind of fatty 'hump' an idea was first suggested but then dismissed as extremely improbable ("äußerst unwahrscheinlich") in a predator by Stromer (1915), and instead he favoured a narrow sail comparable to the Permian synapsids such as Dimetrodon and Edaphosaurus. Subsequently, other authors have suggested a bison or camelid like hump (Bailey, 1997) or a sail to facilitate thermoregulation (Bailey, 1997; Bertin, 2010). The former is unlikely given the structure of the expanded neural spines (Ibrahim et al., 2014) although the latter is worthy of consideration. Several other dinosaurian taxa have convergently acquired similar structures including those that were sympatric with spinosaurs (Bertin, 2010) and it has also been suggested that bodies of water may have helped large spinosaurs regulate body temperature (Amiot et al., 2010b). It has recently been suggested that the sail in Spinosaurus may have functioned as a mechanical aid during swimming (Gimsa et al., 2015) but this relies on the animal being an able swimmer in deep water and is based on a number of unverifiable assumptions about the anatomy and locomotion of these animals and so is not here considered a viable hypothesis. No detailed work has been done to assess the possible 'mechanical' functions of the sail in these animals, though certainly it would have increased the surface area of the animals considerably and could potentially at least serve as thermoregulatory device (Bertin, 2010), though this does not rule out other hypotheses (Holtz et al., 2004; Bertin, 2010).

Exaggerated structures like the sail have been considered to be features that function as 'species recognition' characters (Padian \& Horner, 2011) but this hypothesis is problematic (e.g. see Hone \& Naish, 2013). Such features are often best considered as socio-sexual signals (i.e. they may function as sexually selected characters and / or to suggest social dominance) and some form of signaling has been repeatedly suggested for the sail (Holtz et al., 2004; Bertin, 2010). Ibrahim et al., (2014) suggested that the sail would serve as a signaling device in Spinosaurus while the animal was swimming but the (admittedly much smaller) cranial crest would still be visible too and this would only be effective in shallow water if the animal was sufficiently dense that could walk on the bottom of lakes and rivers (a possibility given the thickened limb bones in this taxon). It was suggested by Hone et al., (2012) that the proportionally small size of the cranial crest in theropods may have been a trade-off between socio-sexual signaling and to avoid warning prey of their presence. As such a spinosaur that was primarily above water feeding into it with the head, a small cranial crest coupled with a large display 
structure on the body would fit this hypothesis and may at least partially explain the presence of such a feature that is otherwise absent in other large theropods.

\section{Conclusions}

Spinosaurs have now been known to science for a century and recent finds have greatly extended the number of skeletal remains of the spinosaurs and provided considerable new information on this group of theropods. However, despite a very wide distribution in both time and space, the clade is known primarily from isolated teeth and much of their anatomy, ecology and evolution remains relatively poorly known. Conflicting taxonomic interpretations and the limited descriptions available of key specimens remain an issue for spinosaur research, but new discoveries and increasing research interest point to a better understanding of this group in the near future.

\section{Acknowledgements}

We thank $\mathrm{Xu}$ Xing for his invitation to submit this article and editorial work on it. Our thanks to Serjoscha Evers for discussions and his suggestions on an early version of this manuscript and to Darren Naish for discussion on Baryonyx. Eric Buffetaut is thanked for his review and helpful comments on an earlier version of the manuscript. We thank Scott Hartman and Matt van Rooijen for their generosity over the use of their artwork in figures 1 and 6 respectively. We thank Christiano Dal Sasson, José Ignacio Canudo, Ronan Allain, and Serjoscha Evers for kindly contributing photographs of specimens that were used for various figures.

\section{References:}

Allain, R., Xaisanavong, T., Richir, P., and Khentavong, B., 2012. The first definitive Asian spinosaurid (Dinosauria: Theropoda) from the Early Cretaceous of Laos. Naturwissenschaften, 99: 369-377.

Amiot, R., Buffetaut, E., Lecuyer, C., Wang, X., Boudad, L., Ding, Z., Fourel, F., Hutt, S., Martineau, F., Medeiros, M.A., Mo, J., Simon, L., Suteethorn, V., Sweetman, S., Tong, H., Zhang, F., and Zhou, Z., 2010a. Oxygen isotope evidence for semi-aquatic habits among spinosaurid theropods. Geology, 38: 139-142.

Amiot, R., Wang, X., Lécuyer, C., Buffetaut, E., Boudad, L., Cavin, L., Ding, Z., Fluteau, F., Kellner, A.W., Tong, H. and Zhang, F., 2010b. Oxygen and carbon isotope compositions of middle Cretaceous vertebrates from North Africa and Brazil: Ecological and environmental significance. Palaeogeography, Palaeoclimatology, Palaeoecology, 297: 439-451.

Bailey, J.B., 1997. Neural spine elongation in dinosaurs: sailbacks or buffalo-backs? Journal of Paleontology, 71: $1124-1146$

Barker, C., Dyke, G., Naish, D., Newham, E., and Orestis, K., 2015. Complex neurovascular network in the rostrum of Neovenator salerii. SVPCA Abstract Volume, Southampton.

Barrett, P.M., Benson, R.B.J., Rich, T.H., and Vickers-Rich, P., 2011. First spinosaurid dinosaur from Australia and the cosmopolitanism of Cretaceous dinosaur faunas. Biology Letters 7: 933-936.

Benson, R.B.J., 2010. A description of Megalosaurus bucklandii (Dinosauria:, Theropoda) from the Bathonian of the UK and the relationships of Middle Jurassic theropods. Zoological Journal of the Linnean Society, 158: 882-935.

Benyoucef, M., Läng, E., Cavin, L., Mebarki, K., Adaci, M., and Bensalah, M., 2015. Overabundance of piscivorous dinosaurs (Theropoda: Spinosauridae) in the mid-Cretaceous of North Africa: the Algerian dilemma. 
Cretaceous Research, 55: 44-55.

Bertin, T., 2010. A catalogue of material and review of the Spinosauridae. PalArch's Journal of Vertebrate

Palaeontology, 7: 1-39.

Blumenschine, R.J., 1986. Carcass consumption sequences and the archaeological distinction of scavenging and hunting. Journal of Human Evolution, 15: 639-659.

Buffetaut, E. 1992.Remarks on the Cretaceous theropod dinosaurs Spinosaurus and Baryonyx. Neues Jahrbuch für Geologie und Paläontologie, Monatshefte, 2: 88-96

Buffetaut, E., 2008 Spinosaurid teeth from the Late Jurassic of Tengaduru, Tanzania, with remarks on the evolutionary and biogeographical history of the Spinosauridae. In: Mazin, J.-M., Pouch, J., Hantzpergue, P., and Lacombe, V. (eds), Mid-Mesozoic life and environments. Lyon: Documents des Laboratoires de Géologie Lyon: 26-28.

Buffetaut, E., 2010. Spinosaurs before Stromer: early finds of spinosaurid dinosaurs and their interpretations. Geological Society, London, Special Publications, 343: 175-188.

Buffetaut, E., 2012. An early spinosaurid dinosaur from the Late Jurassic of Tendaguru (Tanzania) and the evolution of the spinosaurid dentition. Oryctos,10: 1-8.

Buffetaut, E., and Ingavat, R., 1986 Unusual theropod dinosaur teeth from the Upper Jurassic of Phu Wiang, northeastern Thailand. Revue de Paléobiologie, 5: 217-220.

Buffetaut, E., Martill, D.M., and Escuillié, F., 2004. Pterosaurs as part of a spinosaur diet. Nature, 430: 33.

Buffetaut, E., Suteethorn, V., Tong, H., and Amiot, R., 2008. An Early Cretaceous spinosaurid theropod from Southern China. Geological Magazine, 145: 745-748.

Carrano, M.T., Benson, R.B., and Sampson, S.D., 2012. The phylogeny of Tetanurae (Dinosauria: Theropoda). Journal of Systematic Palaeontology, 10: 211-300.

Canudo, J.I., Gasulla, J.M., Gómez-Fernández, D., Ortega, F., Sanz, J.L., and Yagüe, P., 2008. Primera evidencia de dientes aislados atribuidos a Spinosauridae (Theropoda) en el Aptiano inferior (Cretácico Inferior de Europa: Formación Arcillas de Morella (España)). Ameghiniana, 45: 649-662.

Charig, A.J., and Milner, A.C., 1986. Baryonyx, a remarkable new theropod dinosaur. Nature, 324: 359-361.

Charig, A.J., and Milner, A.C., 1997. Baryonyx walkeri, a fish-eating dinosaur from the Wealden of Surrey. Bulletin of the Natural History Museum Geology, 53: 11-70.

Dal Sasso, C., Maganuco, S., Buffetaut, E., and Mendez, M., 2005. New information on the skull of the enigmatic theropod Spinosaurus, with remarks on its size and affinities. Journal of Vertebrate Paleontology, 25: 888-896.

Evers, S.W., Rauhut, O.W., Milner, A.C., McFeeters, B., and Allain, R., 2015. A reappraisal of the morphology and systematic position of the theropod dinosaur Sigilmassasaurus from the "middle" Cretaceous of Morocco. PeerJ, 3: p.e1323.

Foffa, D., Cuff, A.R., Sassoon, J., Rayfield, E.J., Mavrogordato, M.N., and Benton, M.J., 2014. Functional anatomy and feeding biomechanics of a giant Upper Jurassic pliosaur (Reptilia: Sauropterygia) from Weymouth Bay, Dorset, UK. Journal of Anatomy, 225: 209-219.

Fowler, D.W., and Hall, L.E., 2011. Scratch-digging sauropods, revisited. Historical Biology, 23: 27-40.

Gimsa, J., Sleigh, R., and Gimsa, U., 2015.The riddle of Spinosaurus aegyptiacus' dorsal sail. Geological Magazine, 153: 544-547.

Glut, D.F., 1982. The New Dinosaur Dictionary. Secaucus, NJ: Citadel Press.

Halstead, L.B., 1975. The Evolution and Ecology of the Dinosaurs. London: Eurobook Limited. 
Hendrickx, C., and Mateus, O., 2014. Abelisauridae (Dinosauria: Theropoda) from the Late Jurassic of Portugal and dentition-based phylogeny as a contribution for the identification of isolated theropod teeth. Zootaxa, 3759: $1-74$.

Hendrickx, C., Mateus, O., and Buffetaut, E., 2016. Morphofunctional Analysis of the Quadrate of Spinosauridae (Dinosauria: Theropoda) and the Presence of Spinosaurus and a Second Spinosaurine Taxon in the Cenomanian of North Africa. PLoS ONE, 11: e0144695.

Hildebrand, M., and Goslow, Jr, G.E., 2001. Analysis of Vertebrate Structure. New York, Wiley.

Holtz, T.R.J., 1998. Spinosaurs as crocodile mimics. Science, 282: 1276-1277

Holtz, T.R.J., Molnar, R.E., and Currie, P.J., 2004. Basal Tetanurae. In: Weishampel, D.B., Dodson, P., Osmólska, H., (eds), The Dinosauria. Berkeley: University of California Press: 71-110.

Hone, D.W.E., and Faulkes, C.J., 2014. A proposed framework for establishing and evaluating hypotheses about the behaviour of extinct organisms. Journal of Zoology, 292: 260-267.

Hone, D.W.E., and Naish, D., 2013. The 'species recognition hypothesis' does not explain the presence and evolution of exaggerated structures in non-avialan dinosaurs. Journal of Zoology, 290: 172-180.

Hone, D.W.E. and Rauhut, O.W.M., 2010. Feeding behaviour and bone utilization by theropod dinosaurs. Lethaia, 43: 232-244.

Hone, D.W.E., Xu, X., and Wang, D.-Y., 2010. A probable baryonychine (Theropoda: Spinosauroidae) tooth from the Upper Cretaceous of Henan Province, China. Vertebrata PalAsiatica, 48: 19-26.

Hone, D.W.E., Naish, D., and Cuthill, I.C., 2012. Does mutual sexual selection explain the evolution of head crests in pterosaurs and dinosaurs? Lethaia, 45: 139-156.

Ibrahim, N., Sereno, P.C., Dal Sasso, C., Maganuco, S., Fabbri, M., Martill, D.M., Zouhri, S., Myhrvold, N., Iurino, D.A., 2014. Semiaquatic adaptations in a giant predatory dinosaur. Science, 345: 1613-1616

Kellner, A.W.A., Azevedo, S.A.K., Machado, E.B., Carvalho, L.B. de, and Henriques, D.D.R., 2011. A new dinosaur (Theropoda, Spinosauridae) from the Cretaceous (Cenomanian) Alcântara Formation, Cajual Island, Brazil. Anais da Academia Brasileira de Ciências, 83: 99-108.

Kellner, A.W.A., and Campos, D. de A., 1996. First Early Cretaceous theropod dinosaur from Brazil with comments on Spinosauridae. Neues Jahrbuch für Geologie und Paläontologie, Abhandlungen, 199: 151-166.

Kitchener, A., 1987. Function of Claws' claws. Nature, 325: 114.

Martill, D.M., Cruickshank, A.R.I., Frey, E., Small, P.G., and Clarke, M., 1996. A new crested maniraptoran dinosaur from the Santana Formation (Lower Cretaceous) of Brazil. Journal of the Geological Society, London, 153: 5-8.

Mateus, O., Araújo, R., Natário, C., and Castanhinha, R., 2011. A new specimen of the theropod dinosaur Baryonyx from the early Cretaceous of Portugal and taxonomic validity of Suchosaurus. Zootaxa, 2827: 54-68.

Milner, A.R., Harris, J.D., Lockley, M.G., Kirkland, J.I. and Matthews, N.A., 2009. Bird-like anatomy, posture, and behavior revealed by an Early Jurassic theropod dinosaur resting trace. PloS one, 4: p.e4591.

Naish, D., 2011. Theropod dinosaurs. English Wealden fossils. London: The Palaeontological Association, 526-559.

Novas, F.E., Agnolín, F.L., Ezcurra, M.D., Porfiri, J., and Canale, J.I., 2013. Evolution of the carnivorous dinosaurs during the Cretaceous: the evidence from Patagonia. Cretaceous Research, 45: 174-215

Padian, K., and Horner, J.R. 2011. The evolution of 'bizarre structures' in dinosaurs: biomechanics, sexual selection, social selection or species recognition? Journal of Zoology, 283: 3-17.

Rauhut, O.W.M., 2003. The interrelationships and evolution of basal theropod dinosaurs. Special Papers in Palaeontology, 69: 1-216.

Rauhut, O.W.M., 2011. Theropod dinosaurs from the Late Jurassic of Tendaguru (Tanzania). Special Papers in Palaeontology, 86: 195-239. 
Rayfield, E., Milner, A.C., Xuan, V.B., and Young, P.G., 2007. Functional morphology of spinosaur 'crocodile mimic' dinosaurs. Journal of Vertebrate Paleontology, 27: 892-901.

Richter, U., Mudroch, A., Buckley, L.G., 2013. Isolated theropod teeth from the Kem Kem Beds (Early Cenomanian) near Taouz, Morocco. Paläontologische Zeitschrift, 87: 291-309

Russell, D.A., 1996. Isolated Dinosaur bones from the Middle Cretaceous of the Tafilalt, Morocco. Bulletin du Muséum National d'histoire Naturelle. Section C, Sciences de la terre, Paléontologie, Géologie, Minéralogie, 18: 349-402.

Saikia, P.K., 2013. Indian Gharial (Gavialis gangeticus): Status, Ecology and Conservation. Rare Animals of India, 1: 76.

Sales, M.A., Lacerda, M.B., Horn, B.L., de Oliveira, I.A. and Schultz, C.L., 2016. The “ $\chi$ ” of the Matter: Testing the Relationship between Paleoenvironments and Three Theropod Clades. PloS ONE, 11.

Senter, P., 2005. Function in the stunted forelimbs of Mononykus olecranus (Theropoda), a dinosaurian anteater. Paleobiology, 31: 373-381.

Sereno, P.C., Beck, A.L., Dutheil, D.B., Gado, B., Larsson, H.C.E., Lyon, G.H., Marcot, J.D., Rauhut, O.W.M., Sadleir, R.W, Sidor, C.A., Varricchio, D.D., Wilson, G.P., and Wilson, J.A. 1998. A long-snouted predatory dinosaur from Africa and the evolution of Spinosaurids. Science, 282:1298-1302.

Serrano-Martínez, A., Ortega, F., Sciscio, L., Tent-Manclús, J.E., Fierro Bandera, I., and Knoll, F., 2015 New theropod remains from the Tiourarén Formation (?Middle Jurassic, Niger) and their bearing on the dental evolution in basal tetanurans. Proceedings of the Geologists' Association, 126: 107-118.

Smith, J.B., Lamanna, M.C., Mayr, H., and Lacovara, K.J. 2006. New information regarding the holotype of Spinosaurus aegyptiacus Stromer, 1915. Journal of Paleontology, 80: 400-406.

Soares, D., 2002. An ancient sensory organ in crocodilians. Nature, 417: 241-242.

Stromer, E., 1915. Ergebnisse der Forschungsreisen Prof. Stromers in den Wüsten Ägyptens. II Wirbeltier-Reste der Baharîje-Stufe (unterstes Cenoman). 3. Das Original des Theropoden Spinosaurus aegyptiacus nov. gen., nov. spec. Abhandlungen der Königlich Bayerischen Akademie der Wissenschaften. Mathematischphysikalische Klasse. 28: 1-32.

Stromer, E., 1934. Ergebnisse der Forschungsreisen Prof. E. Stromers in den Wüsten Ägyptens. II. Wirbeltierreste der Baharije-Stufe (unterstes Cenoman). 13. Dinosauria. Abhandlungen der Bayerischen Akademie der Wissenschaften, Mathematisch-naturwissenschaftliche Abteilung, Neue Folge, 22: 1-79.

Sues et al. 1998.

Sues, H.-D., Frey, E., Martill, D.M., and Scott, D.M., 2002. Irritator challengeri, a spinosaurid (Dinosauria: Theropoda) from the Lower Cretaceous of Brazil. Journal of Vertebrate Paleontology, 22: 535-547.

Taquet, P., 1976. Géologie et Paléontologie du Gisement de Gadoufaoua (Aptien du Niger). Paris, Centre National de la Recherche Scientifique, 1-191 (Cahiers de Paléontologie).

Taquet, P., 1984. Une curieuse spécialisation du crâne de certains Dinosaures carnivores du Crétacé: le museau long et étroit des Spinosauridés. Comptes Rendus de l'Academie des Sciences, Série II, 299: 217-222.

Therrien, F., and Henderson, D.M., 2007. My theropod is bigger than yours ... or not: estimating body size from skull length in theropods. Journal of Vertebrate Paleontology. 27: 108-115.

\section{About the first author}

HONE David William Elliott Male; born in 1978 in London, UK; PhD; Lecturer in Zoology, Queen Mary University of London; He is interested in the study of sexual selection and behavior in the fossil record. Email: d.hone@qmul.ac.uk; phone: +44 2078823040 


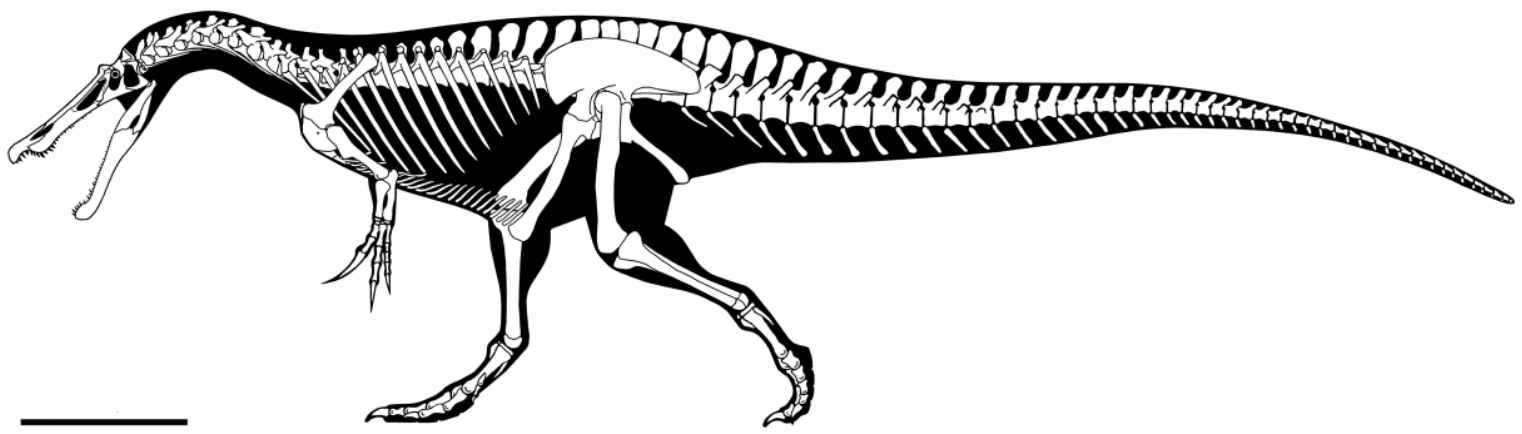

Figure 1: Bauplan of a typical spinosaur - the British baryonychine Baronyx walkeri showing the unusual and elongate cranial morphology, elongate dorsal neural spines and atypical forelimb of the group compared to other basal neotheropods. Scale bar $1 \mathrm{~m}$. Skeletal reconstruction by Scott Hartman, used with permission.

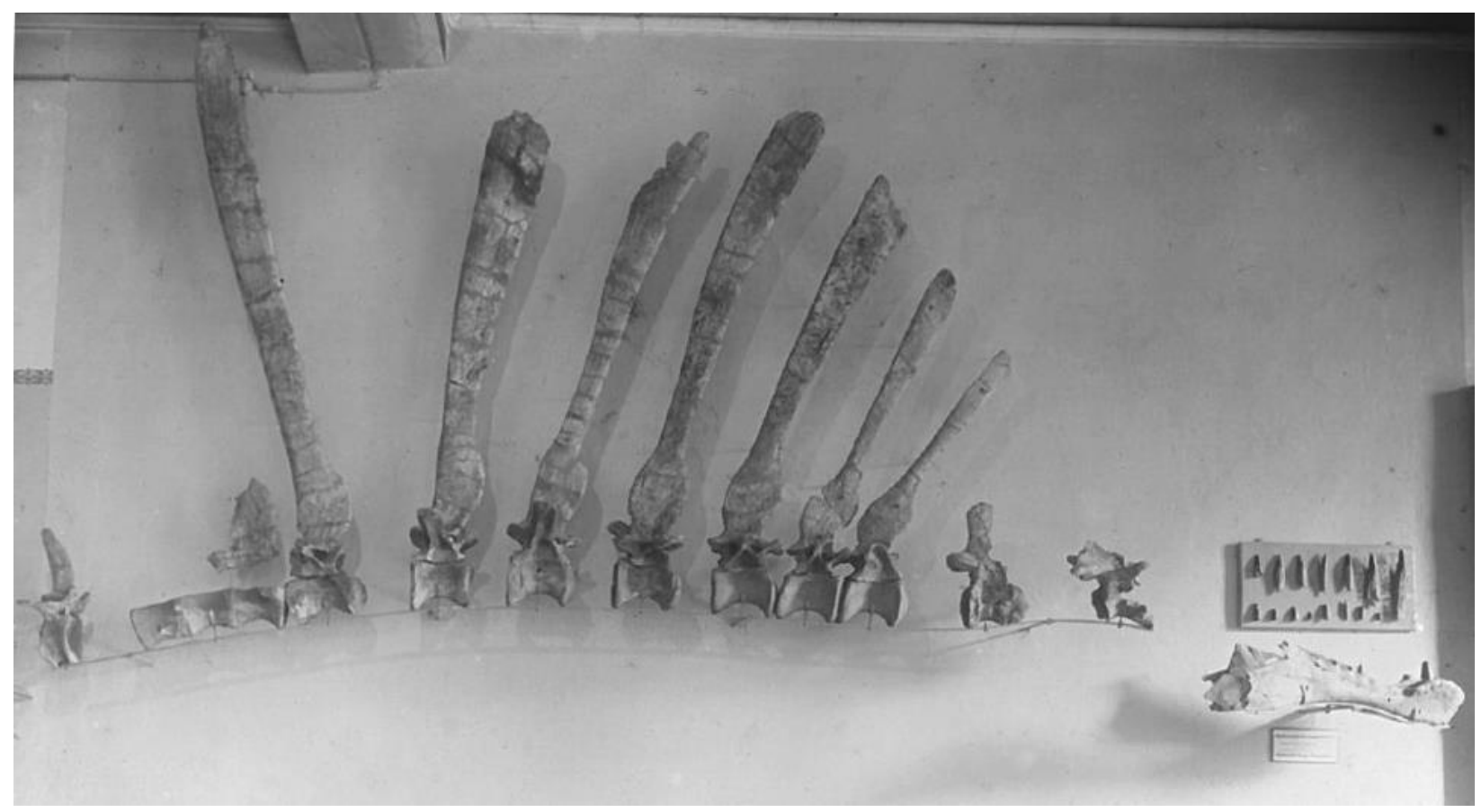

Figure 2. Photograph of the holotype material of Spinosaurus on display in Munich before its loss in 1945. 


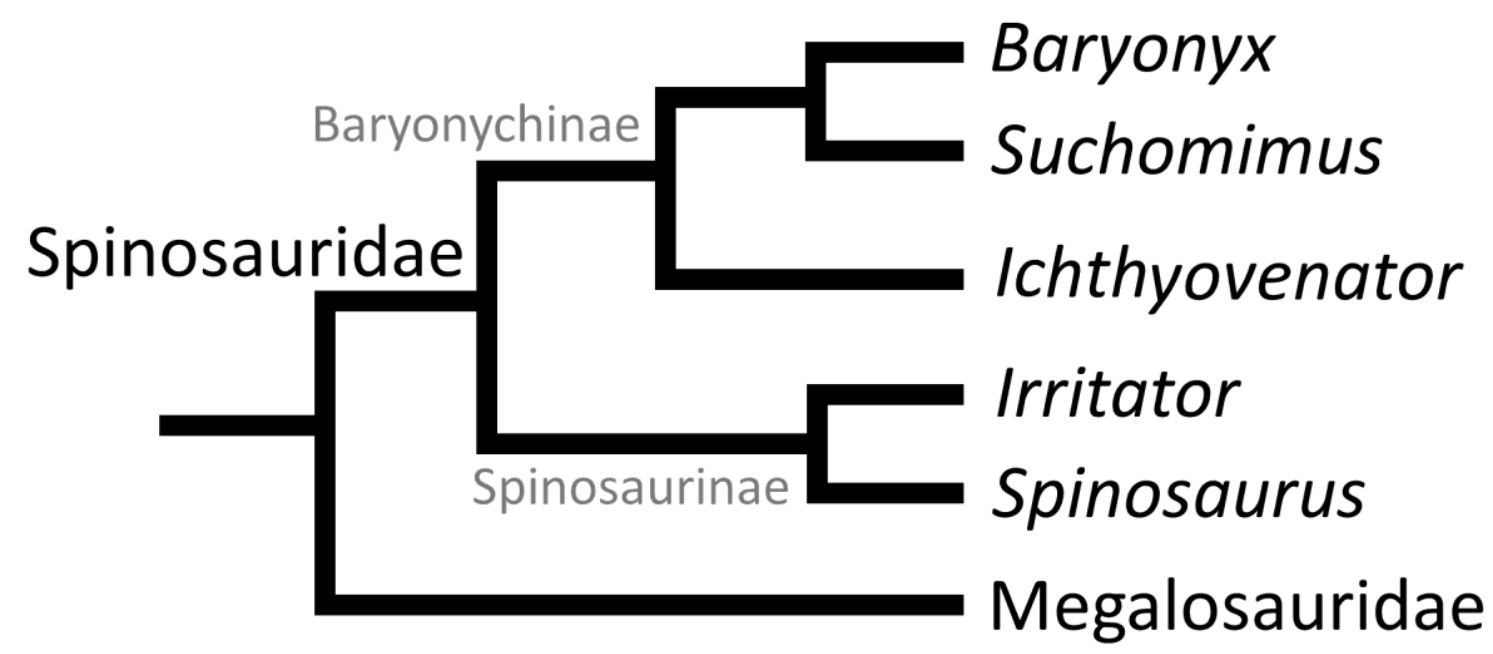

Figure 3. Simple phylogeny of the Spinosauridae, modified from Allain et al., 2012.

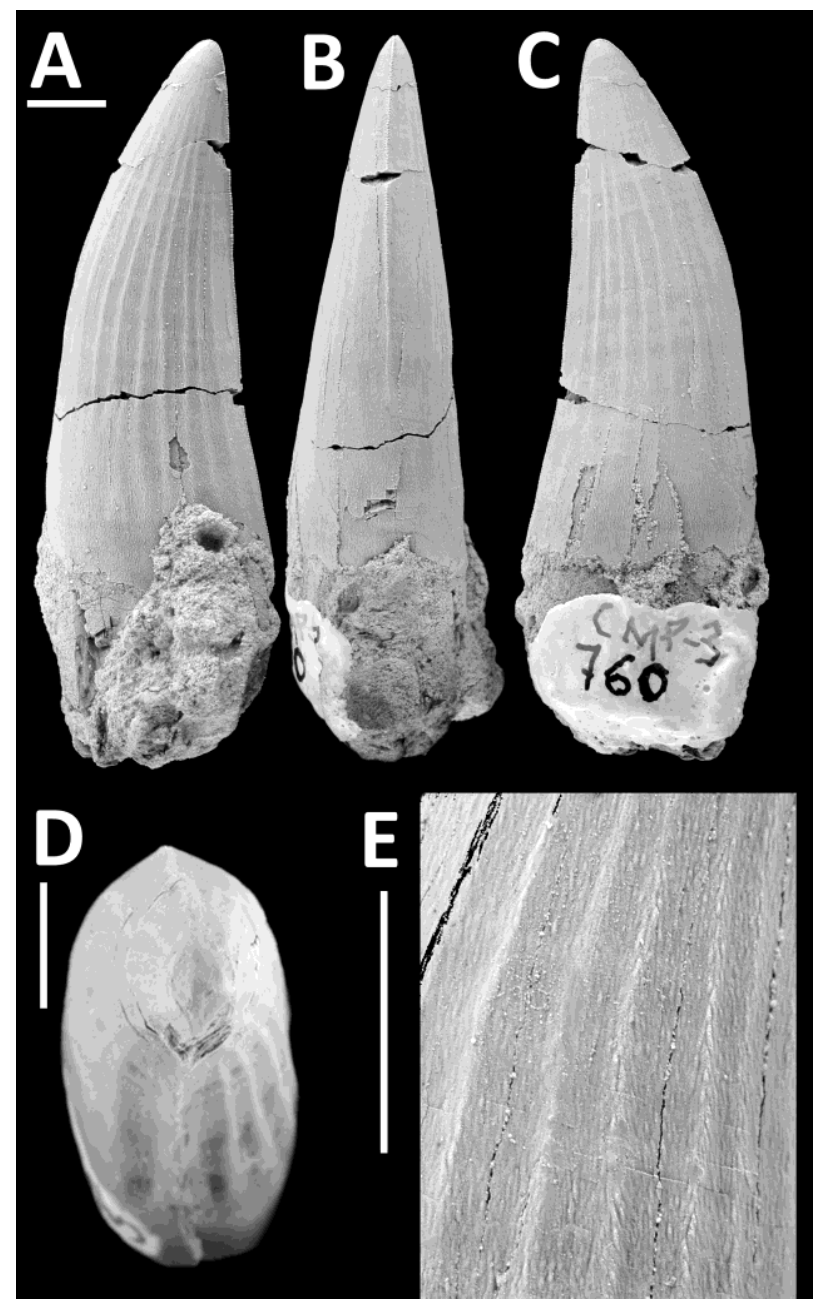


Figure 4. Tooth of a spinosaur (CMP 3760) in A. labial / lingual view, B mesial, C labial / lingual view, D anterior view. These show the limited curvature of the tooth, sub-circualr cross-section and reduced carinae. E. Close up of face of showing the ornamental 'fluting' on the enamel. (Images courtesy of J.I. Canudo). All scales are $5 \mathrm{~mm}$.

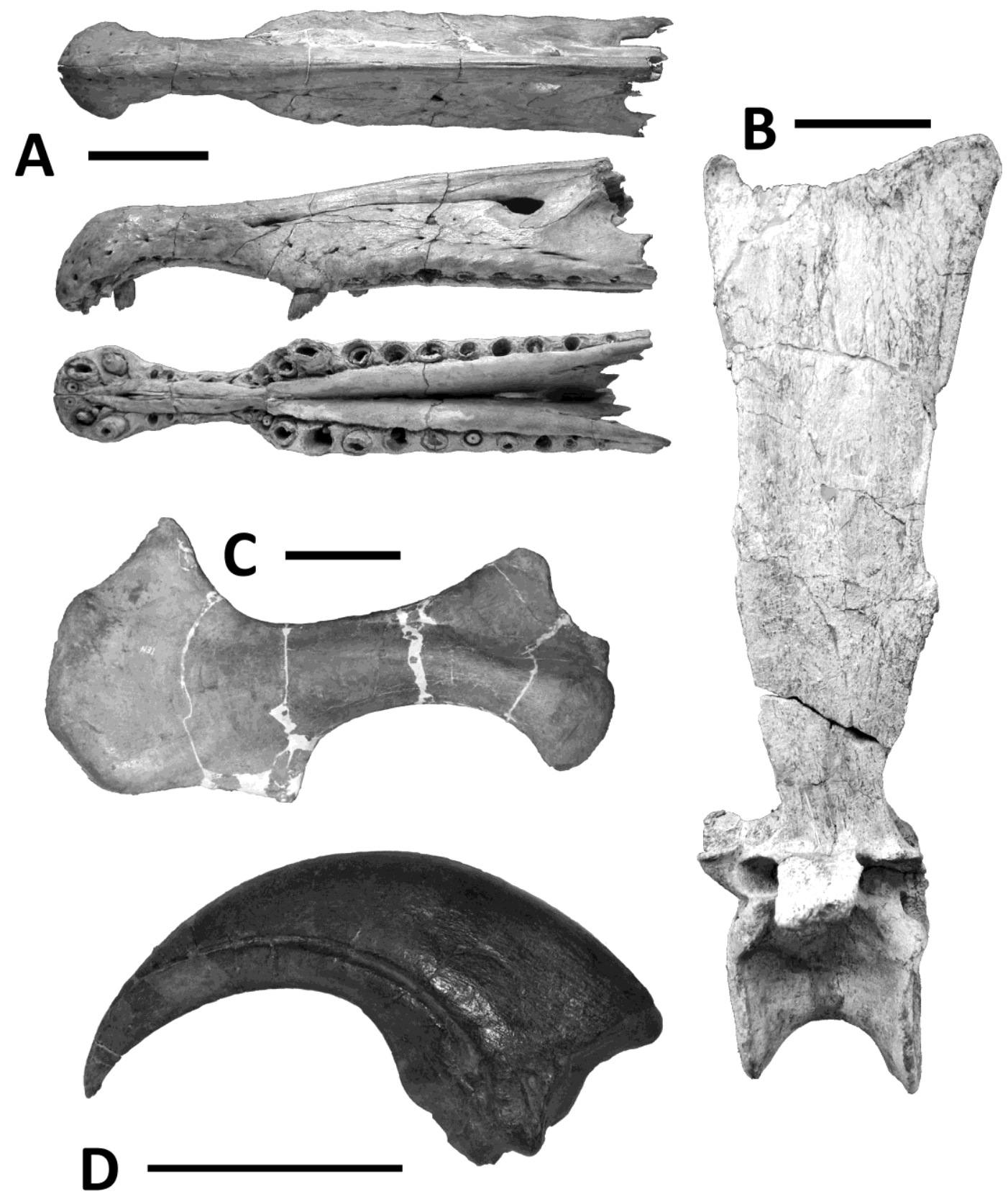

Figure 5. Montage of the major anatomical features of spinosaurids. A. The elongate rostrum of Spinosaurus (MSNM V4047 - courtesy C. Dal Sasso) showing the terminal rosette. B. The greatly expanded and elongate dorsal neural spine of Ichthyovenator (MDS BK10-01 to 15 - courtesy of, and copyright to R. Allain). C. The unusual forelimb of Baryonyx showing the robust humerus (left, lateral view) and enlarged first manual ungual (BMNH R9951 - humerus courtesy of S. Evers; claw, DWEH). All scales are $100 \mathrm{~mm}$. 


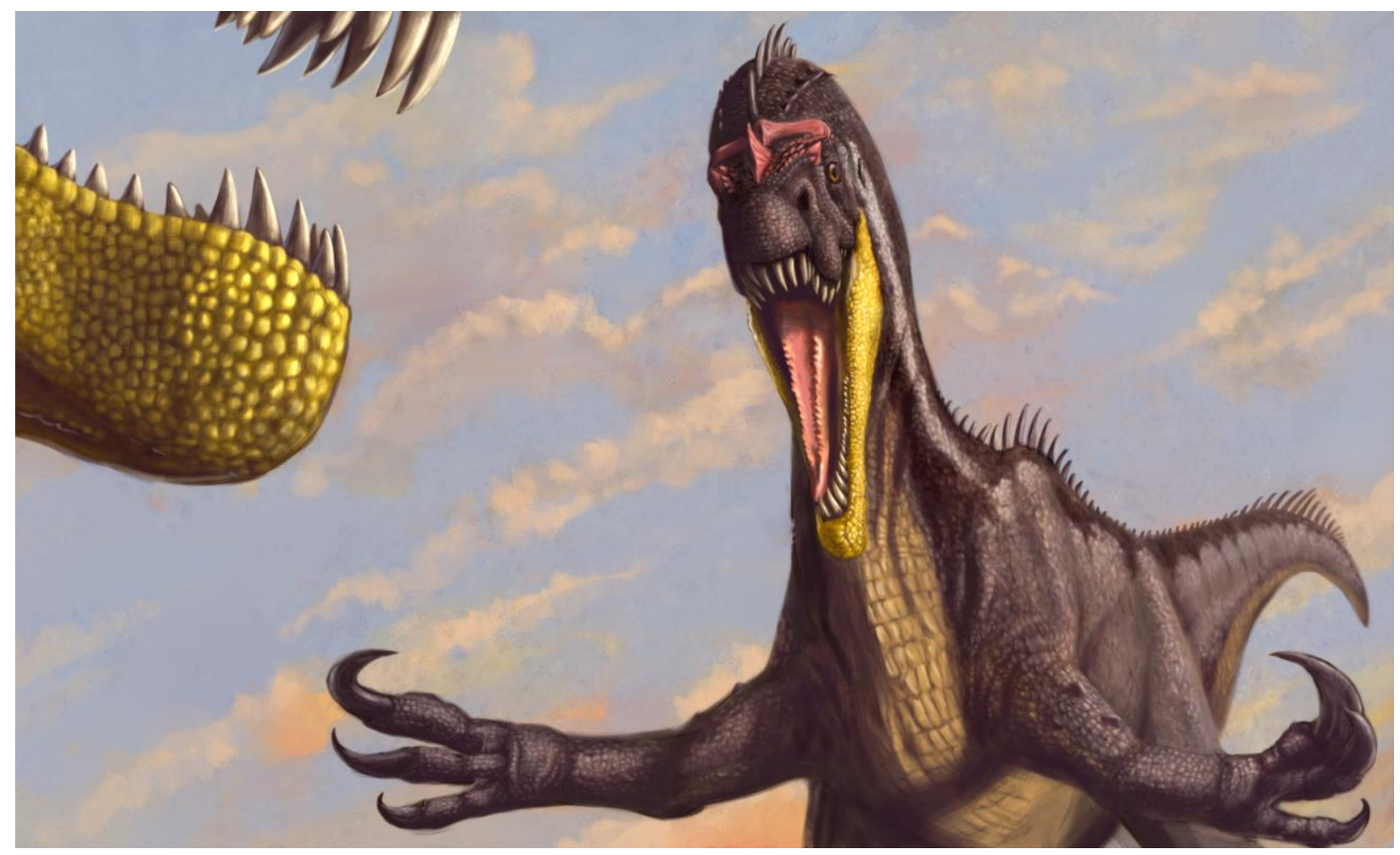

Figure 6. Life reconstruction a spinosaurid exhibiting a speculative threat display posture. By Matt van Rooijen, used with permission. 